\title{
Managing and Enhancing Employee Engagement
}

\author{
Eric Flamholtz PhD \\ Professor Emeritus (Recalled) \\ Anderson School of Management \\ The University of California, Los Angeles \\ USA
}

\begin{abstract}
There has been increasing interest in the concept of "Employee Engagement." The term itself has an intuitive appeal with positive connotations. However, although the concept is now widely used, it is still lacking in precision. The purpose of this paper is to provide a framework that can be useful to managers as well as researchers to understand the nature and potential value of the construct of employee engagement as well as the providing a platform for the development of tools for measuring engagement.
\end{abstract}

Keywords: Engagement, Employee Engagement, Degrees of engagement

There has been increasing interest in the concept of "Employee Engagement." The term itself has an intuitive appeal with positive connotations. However, the concept of engagement has not been defined in a generally accepted way. However, although the concept is now widely used, it is still lacking in precision. As Ferguson (2007) has stated, unless employee engagement can be universally defined and measured, it cannot be managed, nor can it be known if efforts to improve it are working. ${ }^{1}$

\section{Introduction}

The purpose of this article is to provide a framework that can be useful to managers as well as researchers to understand the nature and potential value of the construct of employee engagement as well as the status of current methods for measuring engagement.

\section{Definitions of Engagement}

There are two types of definitions: Constitutive or conceptual definitions and operational definitions. A constitutive definition defines a construct in terms of other constructs. An operational definition defines the construct in terms that are susceptible to measurement or operationalization. Both are relevant with respect to the notion of employee engagement. Accordingly, we will provide both conceptual and operational definitions for the concept of employee engagement.

\section{Conceptual Definition}

As used here, "employee engagement" refers to "the degree or level of commitment of employees to the organization that employs them as well as to their role in that organization".

The notion of employee engagement is not binary; employees are neither only "engaged nor disengaged"; rather, there are degrees of engagement along a continuum from "fully engaged" to "fully disengaged."

\section{Operational Definition}

Given this notion, a "fully engaged employee" can be characterized as one that:

Fully identifies with the organization,

- Is motivated to protect the organization

- Is motivated to participate in the achievement of organizations goals.

- Experiences a sense of vicarious pleasure from the success of the enterprise and/ or displeasure from its difficulties and failures.

\footnotetext{
${ }^{1}$ Ferguson, A. (2007) 'Employee engagement: Does it exist, and if so, how does it relate to performance, other constructs and individual differences?' [online] Available at: http://www.lifethatworks.com/Employee-Engagement.prn.pdf
} 
- Views an attack on the organization as an attack on him or herself.

Operationally defined, a "fully disengaged engaged employee" can be characterized as one that:

- Fully does not identify with the organization,

- Is not motivated to protect the organization

- Is not motivated to participate in the achievement of organizations goals.

- Does not Experiences a sense of vicarious pleasure from the success of the enterprise and/ or displeasure from its difficulties and failures.

- Is indifferent to an attack on the organization

Accordingly, we can see that that the underlying variables comprising employee engagement are:

- Organizational Identification

- Motivationto perform

- Commitment to the enterprise and its goals

- Protection of the Enterprise.

As we shall see below, it is important to identify the components of employee engagement in order to facilitate its measurement.

\section{The Economic Value of Employee Engagement: An Asset}

The degree of employee engagement can be an "asset" or a liability for an enterprise. A fully engage employee is more likely to remain as an employee and be committed to the achievement of the enterprises vision and goals. Similarly, a fully engaged set of employees constitute a valuable asset.

\section{Theoretical Framework}

Although there has been a considerable amount of theorizing and empirical research on aspects of engagement, there is as of yet no generally accepted model of the determinants of engagement. ${ }^{2}$

\section{The Determinants of Engagement}

Based upon our review of the prior research we can identify two types of determinants of employee engagement: 1)direct drivers" of Engagement and 2) environmental factors supporting or inhibiting engagement.Direct drivers of employee engagement are those things that, by definition, have a direct impact of the degree of employee engagement. The environmental factors supporting or inhibiting engagement by definitions have an indirect impact (but still an impact) upon the degree of employee engagement.

\section{Direct drivers of engagement}

The degree of employee engagement is influenced by several "direct drivers" factors including:

- Leadership practices

- Performance management / Reward systems

- Cultural values of the organization.

The direct factors such as those above are things that are generally controllable by the organization.

Environmental Factors Supporting or Inhibiting Engagement

Some environmental factors supporting or inhibiting engagement include:

- Planning processes

- Communication process

- Decision-making processes

- Interdepartmental coordination

- Openness to innovation and change

Environmental factors such as those above can affect the overall " organizational climate, "which in turn, can impact the degree of employee engagement ${ }^{3}$.

\footnotetext{
${ }^{2}$ See for example, WILLIAM A. KAHN "PSYCHOLOGICAL CONDITIONS OF PERSONALENGAGEMENT AND DISENGAGEMENT AT WORK,” Academy of management Journal, 1990, Vol. 33, No.4, 692-724.

${ }^{3}$ For a discussion of organizational climate, see Benjamin Schneider and Karen Barbara, "Introduction: The Oxford Handbook of Organizational Culture and Climate," in The Oxford Handbook of Organizational Culture and Climate, Oxford Library of Psychology, Oxford University Press, 2014, pp. 3-20
} 


\section{The Measurement of Employee Engagement}

Without measurement, a construct has limited utility for managers and, indeed, researchers. This is true for the construct of employee engagement. The significant of this proposed theoretical framework is that it provides a set of constructions which can be operationalized to measure engagement. Specifically, the measurement of employee engagement must address the four key dimensions of engagement: Identification, Motivation, Commitment and Protection). We have developed atool to measure employee engagement, and are in the process of further research on its validation and application.

\section{How to Create Employee Engagement}

As noted above, the direct drivers of employee engagement are those things that, by definition, have a direct impact of the degree of employee engagement. There are three primary direct drivers of employee engagement:"

- Leadership practices

- Performance management/Reward systems (Human resources practices)

- Cultural values and norms of the organization. ${ }^{5}$

The role of each is discussed, in turn, below.

\section{Impact of Leadership Practices on Employee Engagement}

"Leadership practices" refer to both leadership styles as well as the performance of certain key leadership tasks. ${ }^{6}$ It has been well recognized that leadership practices can impact employee engagement. Legendary researchers ranging from Rensis Likert to Fred Fiedler and many others have examined the role of leadership styles and its impact upon what has been recently termed employee engagement. ${ }^{7}$ Their key finding is that the so-called "participative style" of leadership leads to enhanced employee engagement. Specifically, the underlying notion is that participation in decisions leads to enhanced productivity. In addition, research by Seashore and Bowers indicated that there are several key operational "tasks" of leadership that are independent of particular leadership styles but impact employee performance. ${ }^{8}$ These key tasks include: focus upon goals, works facilitation, interaction facilitation, employee support and development. ${ }^{9}$ Our own more recent research on the tasks of what can be termed "strategic leadership" has similarly identified key things that impact organizational effectiveness and success. ${ }^{10}$ The underlying notion is that performance of these leadership tasks can enhance the engagement of people at work.

It must be noted however that leadership practices are a two edged sword. Certain leadership practices can demotivate people (or lead to decreased engagement) as well as to increased engagement. Accordingly the selection and utilization of an optimal style of leadership and the performance of the key leadership tasks are critical to developing a cadre of engaged employees. For example, although the late Steve Jobs was clearly a brilliant visionary, he was also regarded as an abusive manager, who tended to demoralize and disengage people. In contrast, Howard Schultz at Starbucks was both a brilliant visionary but also very accomplished in creating an environment that fostered employee engagement. It is also important to note that people can change their leadership styles and practices. For example, the legendary Jack Welsh was called "Neutron Jack" early in his career at GE--and this nickname was not intended as a complement! However, Welsh later changed his style with coaching and became known as an iconic corporate leader.

\section{Impact of Performance Management/Human Resource Practiceson Employee Engagement}

A second key factor that directly impacts the degree of employee engagement is "Performance management/Human Resource Practices." The variable "Performance Management/Human Resource Practices" refers to processes and systems designed to motivate and reinforce the behavior of organizational members. Performance Management/Human Resource Practices include goal setting, performance appraisals and compensation methods and systems. ${ }^{11}$

\footnotetext{
${ }^{4}$ For information about this measurement tool, please contact Eric Flamholtz, PhD, at: ef@ Mgtsystems.com.

${ }^{5}$ Eric Flamholtz and Yvonne, Corporate Culture: The Ultimate Strategic Asset, Stanford University Press, 2011.

${ }^{6}$ See Eric Flamholtz and Yvonne Randle, Growing Pains, Wiley, 2016.

${ }^{7}$ See Eric Flamholtz and Yvonne Randle Growing Pains. See also the historically relevant Rensis Likert, New Patters of Management, McGraw-Hill, 1961.; The Human Organization: Its Management and Value, McGraw-Hill, 1967;

${ }^{8}$ The key tasks of leadership are summarized in Eric Flamholtz and Yvonne Randle, Growing Pains: Building Sustainably Successful Organizations, Wiley, 2016.

${ }^{9}$ For further discussion of these key tasks, see Growing Pains, chapters $9 \& 12$.

${ }^{10}$ See Eric Flamholtz, “The Leadership Molecule Hypothesis: Implications for Entrepreneurial Organizations," International Review of Entrepreneurship. (2011) Volume 9, Issue no. 3, pp. 1-23.

${ }^{11}$ For further discussion of performance management, see Growing Pains, chapter 8.
} 
The underlying notion is that reward systems such as for incentive compensation can create or enhance alignment between individuals and organizational goals. Even more powerful are stock option programs that create true "employee ownership." Unfortunately, many companies neglect the power of this variable to enhance engagement. Specifically, I have observed that performance management/reward systems are often poorly designed in many companies, both large and small. Also, even where a performance management/reward system actually exists on paper with the potential power to motivate, I have observed the failure to conduct performance reviews leading to employee confusion about what leads to rewards.

\section{Impact of Cultural Values and Norms on Employee Engagement}

The third key factor that directly impacts the degree of employee engagement is "Cultural values and related norms." "Cultural values and related norms" refer to the core values and related norms of a business enterprise. "Values" refer to those things that are most important to an enterprise, while "norms" refer to specified behaviors that demonstrate, are consistent with and also implement values. A key aspect of culture involves the treatment of people. This was perhaps best stated by Howard Schultz, founder and Chairman of Starbucks, who expressed it this way: "The way we treat our people affects the way they treat our customers and in turn our financial performance."

\section{Key Implications}

The degree or level of commitment of employees to the organization that employs them (or what we refer to as "employee engagement") is determined by a number of factors. Three primary or key factors are leadership processes, Human Resource Practices/reward systems, and corporate culture. All of these factors are subject to managerial control. They ought to be viewed as key "levers"or drivers of employee engagement.

Accordingly, if people are treated well and high performance is both expected and rewarded, then people are more likely to be engaged. If people are not treated well and/or if high performance standards are not in place and rewarded, then people are more likely to be disengaged with resulting apathy indifference to the organization and its goals, low performance, and high employee turnover.

\section{Future Research}

The theoretical framework presented identifies the key dimension of employee engagement. This framework provides a foundation of a platform for the development of a tool to measure the degree of employee engagement. Without such a measurement tool, the construct is engagement is interesting but has limited usefulness. The next step is to develop a method of actually measuring engagement. This paper is a step on the path towards that objective.

\footnotetext{
${ }^{12}$ For further discussion of culture and culture management, see Growing Pains, chapter 1. See Also Eric Flamholtz and Yvonne Randle, Corporate Culture: The Ultimate Strategic Asset, Stanford University Press, 2011.
} 